\title{
Polymer substrates for flexible photovoltaic cells application in personal electronic systems
}

\author{
K. ZNAJDEK ${ }^{* 1}$, M. SIBIŃSKI ${ }^{1}$, A. STRĄKOWSKA ${ }^{2}$, and Z. LISIK ${ }^{1}$ \\ ${ }^{1}$ Department of Semiconductor and Optoelectronic Devices, Lodz University of Technology, \\ ul. Wólczańska 211/215, 90-924 Łódź, Poland \\ ${ }^{2}$ Institute of Polymer and Dye Technology, Lodz University of Technology, ul. Stefanowskiego 12/16, \\ 90-924 Łódź, Poland
}

\begin{abstract}
The article presents an overview of polymeric materials for flexible substrates in photovoltaic $(P V)$ structures that could be used as power supply in the personal electronic systems. Four types of polymers have been elected for testing. The first two are the most specialized and heat resistant polyimide films. The third material is transparent polyethylene terephthalate film from the group of polyesters which was proposed as a cheap and commercially available substrate for the technology of photovoltaic cells in a superstrate configuration. The last selected polymeric material is a polysiloxane, which meets the criteria of high elasticity, is temperature resistant and it is also characterized by relatively high transparency in the visible light range. For the most promising of these materials additional studies were performed in order to select those of them which represent the best optical, mechanical and temperature parameters according to their usage for flexible substrates in solar cells.
\end{abstract}

Keywords: solar cells, flexible substrates, polymer materials, flexible photovoltaics (PV), flexible electronics.

\section{Introduction}

Personal electronic systems which are designed for monitoring vital signs of the human body, such as: temperature, pulse rate, blood pressure or respiratory rate, as well as the electronic elements enabling communication, require a continuous power supply. Due to the fact that in certain circumstances, constant access to the electricity of standard resources is impossible or at least impeded, a solution of using alternative energy sources for personal electronic systems' power supply is proposed. Lightweight and flexible inorganic photovoltaic (PV) devices based on semiconductor compounds of cadmium telluride (CdTe) and cadmium sulfide (CdS) are considered for this purpose.

Flexible structures of semiconductor PV cells require utilization of an appropriate substrate material. As for organic flexible solar cells, regular polyester foils are successfully used $[1,2]$ in case of no demands according to high temperature processes, for inorganic structures such as $\mathrm{CdTe} / \mathrm{CdS}$, temperature resistance is crucial for the substrate. The substrate for inorganic semiconductor based solar cells, apart from the sufficient flexibility and mechanical strength of the structure, should be characterized by an appropriately high temperature resistance in order to avoid material degradation during the technological processes of cell manufacturing. Furthermore, low unit weight of the substrate is desired, as well as properties allowing deposi-

\footnotetext{
*e-mail: katarzyna.znajdek@p.lodz.pl
}

tion of conducting layers on the surface, in order to create an electrical contact to photovoltaic structure. Additionally, in case of cell manufacturing in superstrate (reversed) configuration, an important parameter of the substrate material is high optical transmittance in the range of solar radiation wavelength suitable for the absorption of the semiconductor material used. Such requirements are exceptionally difficult to meet because flexible transparent substrates have typically low temperature resistance. To fulfil these requirements and omit high temperature problems some investigations of the inorganic PV structures are based on temperature resistant, ultra-thin glass were undertaken [3,4]. Unfortunately, according to the manufacturer (Corning) data, as well as the authors' research tests, these structures are not resistant to serious bending, which makes it only semi-flexible. Another solution might be using polyimide films, which are less transparent than glass, but relatively high temperature resistant and fully flexible. These material have been used in the experiments concerning CIGS and CdTe PV structures [5,6].

\section{Selection of polymer materials}

Essential parameters of questing substrate material for flexible $\mathrm{CdTe} / \mathrm{CdS}$ photovoltaic cells are: lightweight structure, flexibility and resistance for high temperatures. There are some characteristic temperatures important in terms of operation conditions of solar cells and the technological processes of their manufacturing (high temperatures of deposi- 
tion and recrystallization of semiconductor active layers). From this point of view, considering polymer materials, the critical parameters are: maximum continuous operating temperature, wherein there is no degradation of the polymeric structure $-\mathrm{T}_{\max }$ and the decomposition temperature of the polymer $-\mathrm{T}_{\mathrm{d}}$. In the examined group of polymers, only polyimides and polysiloxanes (also called silicone rubbers) are characterized with high maximum operation temperatures that exceed $300^{\circ} \mathrm{C}$ and decomposition temperatures above $500^{\circ} \mathrm{C}[7,8]$.

Finally, basing on available literature and catalogue data, four types of polymer materials have been selected for the set experimental research on their suitability as potential substrates in the technology of thin film flexible PV cells. The first two types, according to catalogue data, are the most thermally stable, specialty polyimide foils represented by commercial products Kapton ${ }^{\circledR}$ (HN type and PV) by DuPont and Upilex-S® produced by UBE America Inc. The third kind is an elastomer material from the group of polysiloxanes, called polydimethylsiloxane (PDMS). It meets the criteria for high flexibility, has the best-in-class temperature resistance and is also characterized by relatively high optical transmittance in the visible light range. Polysiloxane substrates for the presented experiments have been manufactured in the Institute of Polymer and Dye Technology at the Lodz University of Technology and at the current stage they are not yet commercial products. It is an originally developed methyl-vinyl-silicone rubber filled with the pyrogenic silica and cross-linked with the dicumyl peroxide. As the last group, commercial polyethylene terephthalate (PET) foils have been qualified for further research, despite the significantly lower catalogue maximum temperature $\mathrm{T}_{\max }$. PET foils are almost $100 \%$ transparent in a visible light range absorbed by the solar cell. That is a very important property in terms of substrates for manufacturing technology of photovoltaic structures in a superstrate configuration. This reason, as well as its low cost and commercial availability contributed to the decision of including this material to the test group. Table 1 presents selected properties of described polymer materials basing on literature data and producers' characteristics.

\section{Optical properties analysis}

Experiments on polymer substrates, concerning their optical properties, consisted of optical transmittance measurements, both at room temperature and after thermal pro- cesses. Research for each of selected substrates type, including various thicknesses of respective layers, have been conducted in the range of 400 to $800 \mathrm{~nm}$ wavelength. Optical transmittance distribution was determined using spectrophotometer setup equipped with Optel M250 monochromator of the spectral range of $200 \div 800 \mathrm{~nm}$ and 1800 lines $/ \mathrm{mm}$ mesh. Monochromator is connected to the silicon photodetector S1227-16BQ, allowing detection of the electromagnetic radiation within the wavelength range of $200 \div$ $1000 \mathrm{~nm}$. The signal from the detector is being sent to an amplifier (Optel UD 54) which is read and processed by the computer software through the Optel STER-841 driver. The illuminator is a $250 \mathrm{~W}$ halogen lamp with constant characteristics for the wavelength range of $300 \div 1200 \mathrm{~nm}$, equipped with a $24 \mathrm{~V}$ DC power supply, stabilized in the range of $0 \div 11$ A.

Examples of optical transmittance characteristics, obtained for substrates of selected thicknesses, are shown in Fig. 1.

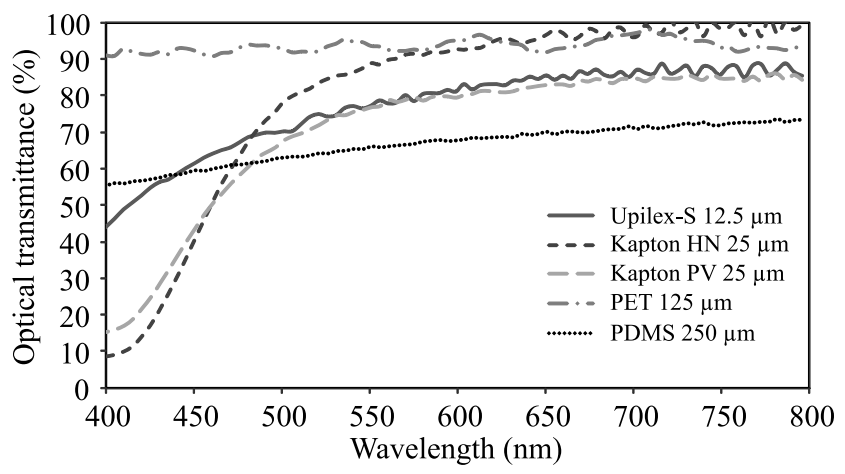

Fig. 1. Examples of the optical transmittance characteristics for selected polymer substrates.

The most uniform distribution of optical transmittance in the investigated range is observed for substrates of PET and PDMS type. Lower level of the transmittance obtained for PDMS substrate is a result of twice higher thickness comparing to PET sample. Unfortunately, at this stage of research we are not able to achieve thinner layers of this material due to the technological processes of manufacturing. Considering Kapton foils, both HN and PV type, it can be observed that absorption in the material, at a large extent causes cutting of the transmitted light from the wavelength range below $500 \mathrm{~nm}$. This is a very disadvantageous phenomenon in terms of required light absorption in photovoltaic cells.

Table 1. Properties of the selected group of polymers [9-12].

\begin{tabular}{lccccc}
\hline Parameter & Upilex-S & Kapton HN & Kapton PV & PDMS & PET \\
\hline Density $\left(\mathrm{g} / \mathrm{cm}^{3}\right)$ & 1.47 & 1.41 & 1.41 & 1.37 & 1.38 \\
Tensile modulus $(\mathrm{GPa})$ & $6.9 \div 9.1$ & 2.5 & $4.5 \div 5.8$ & 0.1 & 3.1 \\
Thermal coefficient of expansion $\left(\mathrm{ppm} /{ }^{\circ} \mathrm{C}\right)$ & $12 \div 20$ & 20 & $14 \div 15$ & 8 & 25 \\
Glass transition temperature $\mathrm{T}_{\mathrm{g}}\left({ }^{\circ} \mathrm{C}\right)$ & $>500$ & $360 \div 410$ & $370 \div 375$ & -50 & 80 \\
Max operation temperature $\mathrm{T}_{\max }\left({ }^{\circ} \mathrm{C}\right)$ & 450 & 400 & 400 & $300 \div 315$ & 120 \\
\hline
\end{tabular}




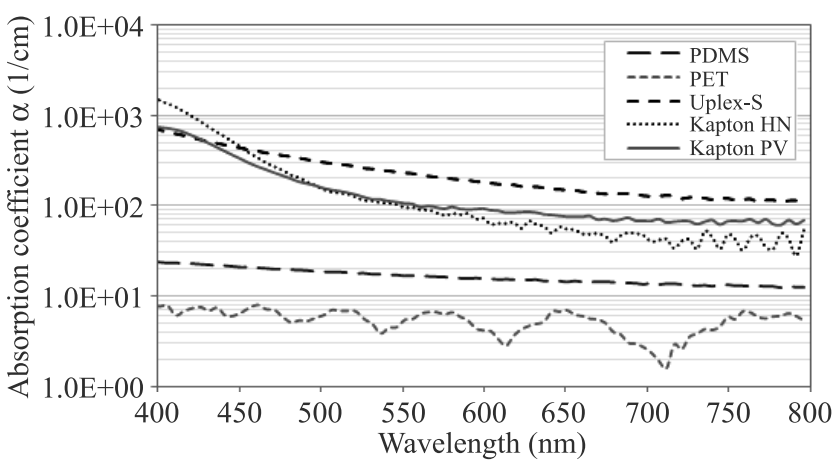

Fig. 2. Absorption coefficient $\alpha$ of the tested materials in the function of the wavelength of solar radiation.

Further step of investigation was focused on the absorption coefficient $(\alpha)$ calculations in order to obtain more accurate and exact characterization of studied materials. Basing on the optical measurements' results, absorption coefficient in the function of the wavelength was determined. Results of these calculations are shown in Fig. 2.

Relatively low light absorption coefficient values obtained in the investigated wavelength range (particularly above $500 \mathrm{~nm}$ ), are beneficial in terms of considered applications. This indicates that solar radiation is substantially transmitted through the investigated polymer layers and light absorption is not occurred in a significant extent.

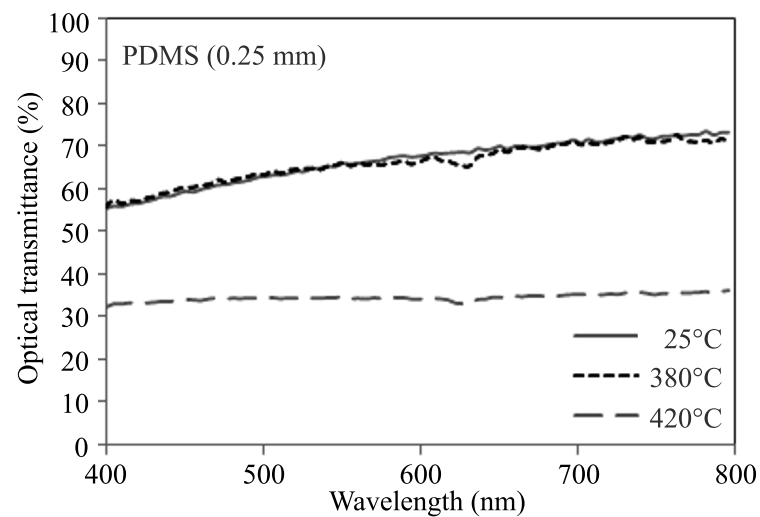

(a)

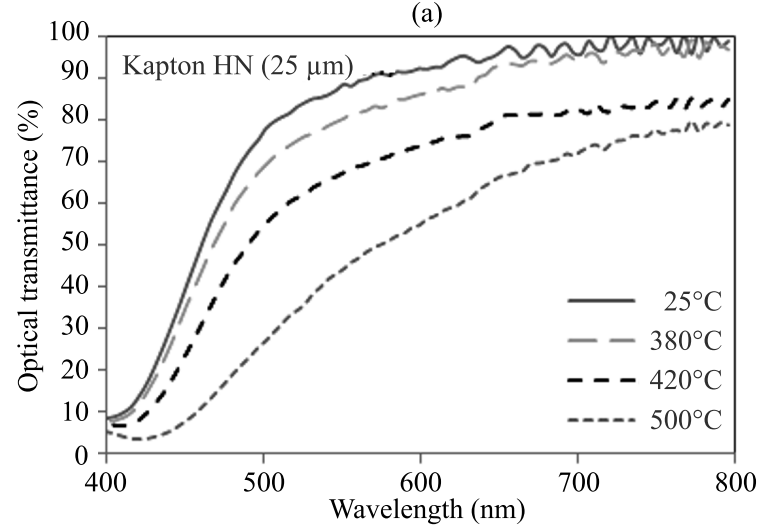

(c)

\section{Temperature resistance investigations}

Since in the superstrate configuration, substrate is a top surface layer of the photovoltaic cell construction, it is essential for the optical transmittance characteristics not to be degraded, both during the production process and while operation of the PV device. Therefore, the next experimental step was an investigation concerning the influence of high temperature treatment on the optical transmittance distribution. Thermal treatment was programmed so as to correspond with the temperature profiles of thin-film solar cells' technology processes. In particular, it concerns recrystallization processes of semiconductor CdTe and CdS layers which comprise annealing of the structures in the temperature of at least $420^{\circ} \mathrm{C}$ for 60 minutes.

For the presented investigation polymer materials listed in Table 1 have been used, however, PET foil was excluded from the experiment due to the fact that its temperature resistance is too low for considering this material as a substrate layer for PV cells. Measurements have been performed at room temperature $\left(25^{\circ} \mathrm{C}\right)$ for foils' samples before subjecting them to the annealing and subsequently after annealing cycle. Temperature of the processes was increased, starting from $100^{\circ} \mathrm{C}$ until the temperature corresponding to a significant reduction of the optical transmittance level. For polyimide foils the critical value of the temperature was about $520^{\circ} \mathrm{C}$, while PDMS have not resisted temperatures higher than $420^{\circ} \mathrm{C}$. Sample results of described measurements are shown in Fig. 3.

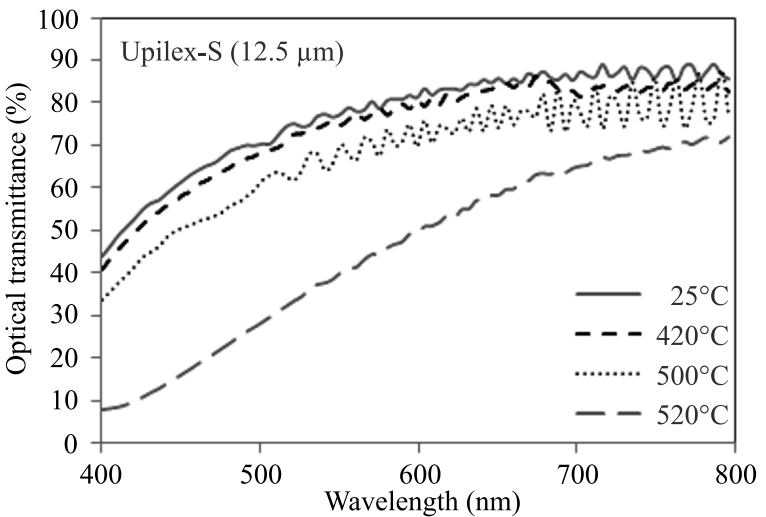

(b)

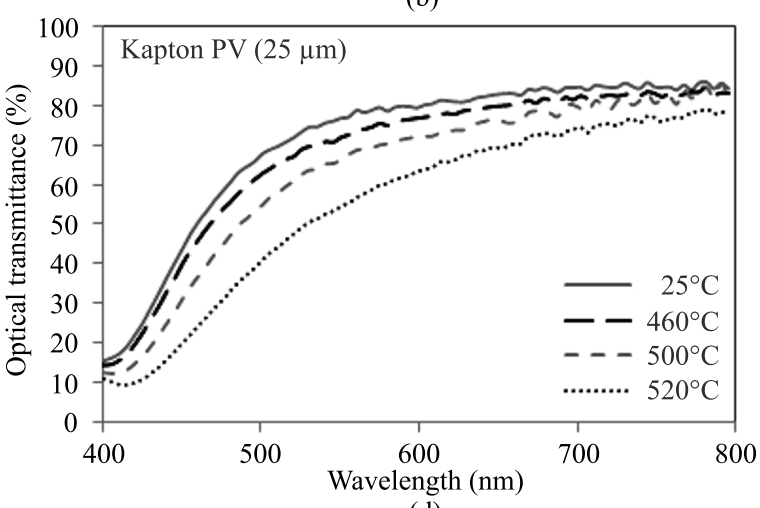

(d)

Fig. 3. Optical transmittance of the tested polymer substrates heated under nitrogen. 
Considering high temperature technological processes, requisite for the formation of the $\mathrm{CdTe} / \mathrm{CdS}$ solar cells' subsequent layers, polyimide materials have been ascertained as highly suitable for substrate layers' applications. Among all investigated polyimides relatively the least favourable results were obtained for Kapton HN film. The first changes in optical transmittance values and distribution have been already observed after temperature treatment in $380^{\circ} \mathrm{C}$. Significantly higher temperature, with no influence on optical parameters of the material, can be applied for Kapton PV foils. It is a product dedicated for flexible thin-film solar cells applications, especially recommended for CIGS PV cells, where high temperature processes are also inherent during manufacturing. Almost perfect optical stability was observed for Upilex-S type substrates up to $420^{\circ} \mathrm{C}$ temperature. Changes in optical transmittance characteristics are relatively slight even for temperatures close to $500^{\circ} \mathrm{C}$. After annealing at $520^{\circ} \mathrm{C}$ almost all investigated polyimide foils significantly lose their properties as transparent materials.

For further comparison, absorption coefficient of investigated materials after thermal cycle in $420^{\circ} \mathrm{C}$ has been calculated in the function of the wavelength. Results of these calculations are shown in Fig. 4. Comparing this plot with Fig. 2 presenting $\alpha$ coefficient before thermal processes, no significant increase of the absorption level has been detected. Only in case of PDMS substrates the absorption coefficient increased clearly. This means that this temperature is suitable for all investigated polyimide substrates processing in terms of technological stages of PV cell manufacturing in superstrate configuration.

When evaluating thermal properties of polymer foils, also their weight loss under the influence of the temperature is an important parameter in terms of PV cells' manufacturing processes. Apart from the percentage weight loss, occurring in the materials after high temperature treatment, in the experiment, the temperature above which tested material loses its elastic properties and transforms into fragile structure was empirically determined. Each process was realized in programmable furnace using 60 minutes constant heating profile and nitrogen atmosphere. Substrates of various thicknesses have been investigated. Commercial foils of Kapton HN by Dupont were available in 3 thicknesses: 12.5, 25 and

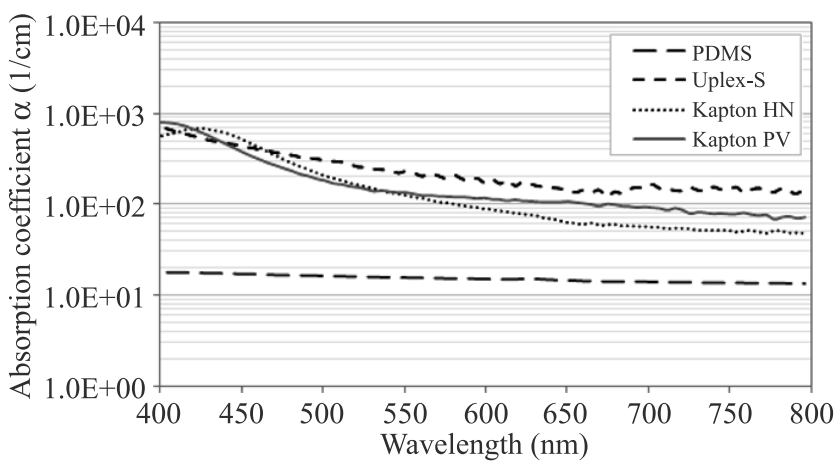

Fig. 4. Absorption coefficient $\alpha$ of tested materials in a function of the wavelength of solar radiation, after thermal treatment in $420^{\circ} \mathrm{C}$.
$50 \mu \mathrm{m}$ and all of them have been tested. Also 3 types of Kapton PV with different thicknesses were used: PV9101 $50 \mu \mathrm{m}$, PV9102 - $38 \mu \mathrm{m}$ and PV9103 - $25 \mu \mathrm{m}$. Polyimide Upilex foils by UBE have been tested using its 5 thicknesses variants, namely: $12.5,25,50,75,125 \mu \mathrm{m}$. Investigated polysiloxane PDMS substrates were much thicker $(0.25$, 0.83 and $1 \mathrm{~mm}$ ) in order to their production technology limitations. However, no effect of the material thickness on the value of the percentage weight loss was observed. Obtained results are shown in Fig. 5.

Presented characteristics show that maximum temperatures, where no significant weight loss is observed for polyimide substrates, both for Kapton and Upilex-S are placed in the upper limit of the catalogue values shown in Table 1. Visible weight loss for these materials cannot be observed until the process temperature exceeds $500^{\circ} \mathrm{C}$. Most preferable in this criterion are Upilex-S films where final weight loss, after thermal annealing at $600^{\circ} \mathrm{C}$, was around $25 \%$. It also appeared that Kapton PV foil type, dedicated for flexible photovoltaics applications, exhibited slightly better thermal properties comparing to standard use Kapton HN.

If considering maximum temperature before losing plastic properties, the most advantageous are again polyimide substrates with the values significantly exceeding $500^{\circ} \mathrm{C}$. Among investigated polyimide foils, the highest maximum temperature of retaining its elastic properties was observed for Upilex-S foils of all tested thicknesses. For investigated Upilex-S films the value of maximum temperature was determined at the level of $560^{\circ} \mathrm{C}$, which is a very advantageous result that places this material at the first position in the rating of temperature resistant polymers for PV substrates applications. Unexpectedly, experimental substrates based on PDMS silicone rubbers showed encouraging temperature parameters. Their maximum temperature of the heat treatment at the level of $420^{\circ} \mathrm{C}$, although is lower than that obtained for Kapton $\left(540^{\circ} \mathrm{C}\right)$ and Upilex-S $\left(560^{\circ} \mathrm{C}\right)$ films, however, extensively exceeds the reported literature values for PDMS, which according to Table 1 are set in the range of $300 \div 315^{\circ} \mathrm{C}$. Polyester PET foils, in accordance with literature data, cannot compete with any other tested

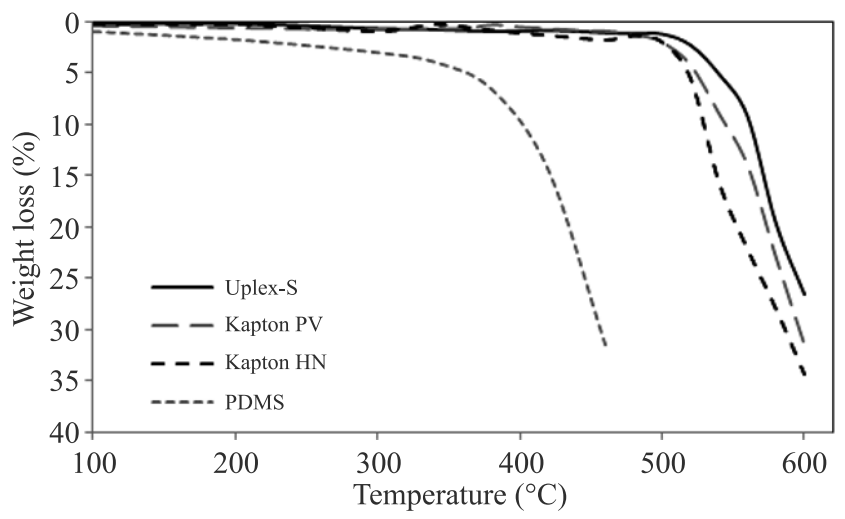

Fig. 5. Percentage weight loss of investigated materials after heating. 
polymer material in terms of temperature resistance. The maximum temperature of PET operation is several times lower than the temperature for investigated polyimides and polysiloxane substrates. PET foil is however characterized by exceptionally favourable optical transmittance values in the visible range of sunlight. This property is extremely useful as a considered additional top protection layer of thin film flexible PV structure.

\section{Conclusions}

Basing on the presented results' analysis, including both temperature and optical investigations, it can be concluded that only polyimide materials met all the requirements and can be selected as substrates for flexible CdTe/CdS structures. Maximum strength temperatures of all tested polyimide foils (Kapton HN, Kapton PV, Upilex-S) exceed $500^{\circ} \mathrm{C}$, although above this value visible weight loss of the materials can be already observed - starting from about $2 \%$ for $500^{\circ} \mathrm{C}$ to even above $30 \%$ when reaching the temperature of $600^{\circ} \mathrm{C}$. Furthermore, relatively high optical transmittance of the films with the lowest thicknesses, predetermine them for applications in flexible PV structures manufactured according to the superstrate configuration. In addition, no significant change in the absorption coefficient values before and after thermal treatment in $420^{\circ} \mathrm{C}$ have been noticed for tested polyimides (á increase at the level of single percent), which is another advantage of these materials. Therefore, according to the established key criterion, optimum temperatures for recrystallization process of $\mathrm{CdS}$ and CTe structures can be determined. These temperatures would be specified in the range above $420^{\circ} \mathrm{C}$ - defined as the minimum temperature of recrystallization of $\mathrm{CdS}$ and CdTe structures [13] and below $500^{\circ} \mathrm{C}-$ as determined by the strength of the substrate materials. Thus, within the presented research, a compromise temperature range enabling the implementation of $\mathrm{CdTe} / \mathrm{CdS}$ photovoltaic structures on flexible polymer substrates have been found.

\section{References}

1. D. Kaduwala, B. Zimmermanna, and U. Würfela, "ITO-free laminated concept for flexible organic solar cells", Solar Energy Materials and Solar Cells 120 B, 449-453 (2014).

2. M. Kaltenbrunner, M.S. White, E.D. Głowacki, T. Sekitani, T. Someya, N.S. Sariciftci, and S. Bauer, "Ultrathin and lightweight organic solar cells with high flexibility", Nature Commun. 3, Art. No. 770 (2012), doi:10.1038/ncomms1772.

3. W.L. Rance, J.M. Burst, D.M. Meysing, C.A. Wolden, M.O. Reese, T.A. Gessert, W.K. Metzger, S. Garner, P. Cimo, and T.M. Barnes, "14\%-efficient flexible CdTe solar cells on ultra-thin glass substrates", Appl. Phys. Lett. 104, 143903 (2014).

4. H.P. Mahabaduge, W.L. Rance, J.M. Burst, M.O. Reese, D.M. Meysing, C.A. Wolden, J. Li, J.D. Beach, T.A. Gessert, W.K. Metzger, S. Garner, and T.M. Barnes, "High-efficiency, flexible CdTe solar cells on ultra-thin glass substrates", Appl. Phys. Lett. 106, 133501 (2015).

5. J. Perrenoud, S. Buecheler, and A.N. Tiwari, "Flexible CdTe solar cells and modules: challenges and prospects", Proc. SPIE 7409, 74090L-74090L-5 (2009).

6. A. Chirilă, S. Buecheler, F. Pianezzi, P. Bloesch, C. Gretener, A.R. Uhl, C. Fella, L. Kranz, J. Perrenoud, S. Seyrling, R. Verma, S. Nishiwaki, Y.E. Romanyuk, G. Bilger, and A.N. Tiwari, "Highly efficient $\mathrm{Cu}(\mathrm{In}, \mathrm{Ga}) \mathrm{Se}_{2}$ solar cells grown on flexible polymer films", Nature Materials 10, 857-861 (2011).

7. M.B. Ahmad, Y. Gharayebi, M.S. Salit, M.Z. Hussein, S. Ebrahimiasl, and A. Dehzangi, "Preparation, characterization and thermal degradation of polyimide (4-APS/BTDA)/ $\mathrm{SiO}_{2}$ composite films", Int. J. Molecular Sciences 13, 4860-4872 (2012).

8. B. Kuźnicka and A. Ziller, "Polimery", Materiałoznawstwo, Politechnika Wrocławska, 65-86 (2006). (IN POLISH)

9. Catalogue data: Netzsch, "Thermal Properties of Polymers", http://www.netzsch-thermal-analysis.com.

10. Catalogue data: "UPILEX®-S - Ube Ultra-High Heat-Resistant Polyimide Film", product card, http://www.northamerica.ube.com.

11. Catalogue data: "Summary of properties for Kapton ${ }^{\circledR}$ polyimide films".

12. Catalogue data: "Kapton ${ }^{\circledR} P V 9100$ Series flexible substrates for thin film PV applications".

13. K. Znajdek, "Flexible photovoltaic cells” (,Elastyczne ogniwa fotowoltaiczne"), PhD thesis, Łódź, Poland, 2014. 